intestinal contents from mice given antibiotics promoted the growth of C. difficile, whereas those from untreated mice did not.

The results could explain why people taking antibiotics have a high risk of $C$. difficile infection.

Nature Commun. 5, 3114 (2014)

\section{NEUROSCIENCE}

\section{Drugs help to dull bad memories}

A drug can improve the effectiveness of a behavioural treatment for fearful memories, at least in mice.

Long-term memories of traumatic events, which can result in anxiety disorders, are difficult to treat, in part because they leave epigenetic, or chemical, marks in the genome. Li-Huei Tsai at the Massachusetts Institute of Technology in Cambridge and her colleagues tested an HDAC inhibitor, a drug that clears epigenetic markers, on mice that were conditioned to freeze in fear when they heard a loud sound. Conditioned mice given the drug, and then exposed to the sound in a safe environment, froze much less frequently than mice that did not receive the drug. The inhibitor made it easier to replace the bad memory with a less fearful one by changing the expression of the genes involved in rewiring the brain, the authors say.

Cell 156, 261-276 (2014)

\section{ENTOMOLOGY}

\section{Parasite drives}

\section{host to nectar}

Mosquitoes carrying a malariacausing parasite develop an increased desire for sugar.

Baldwyn Torto of the International Centre of Insect Physiology and Ecology in Nairobi and his colleagues

monitored the

is attraction of

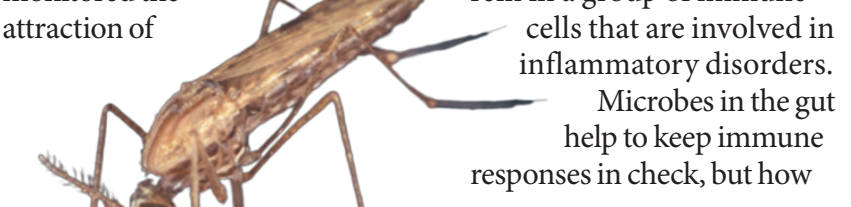

Anopheles gambiae mosquitoes (pictured) to plant odours and the investigative behaviour of the insects around nectar sources. In laboratory experiments, the authors showed that insects infected with Plasmodium falciparum parasites were more attracted to plant odours and demonstrated increased pre-feeding probing activity compared with uninfected individuals.

Plant odours could be used to trap parasite-infected mosquitoes, the authors suggest.

Curr. Biol. http://doi.org/qww (2014)

CLIMATE CHANGE

\section{Strong storms shift landwards} towards the coasts in east Asia in recent decades, resulting in storms of greater intensity making landfall over eastern China, Korea and Japan.

Chang-Hoi Ho of Seoul National University and his colleagues analysed east Asian storm data from 1977 to 2010.

The frequency of intense storms that hit northerly areas has increased, but the intensity of cyclones making landfall farther south - from Vietnam to Taiwan - has not measurably changed.

The researchers suggest that changing atmosphericcirculation patterns resulting from a gradual warming of the western Pacific Ocean have shifted the areas where cyclones develop, moving them to the north and west. Environ. Res. Lett. 9, 014008 (2014)

\section{Microbes control immune cells}

Beneficial gut bacteria secrete compounds that rein in a group of immune cells that are involved in inflammatory disorders. help to keep immune
Cyclone activity has shifted

COMMUNITY CHOICE

The most viewed papers in science

APPLIED PHYSICS

\title{
Device harvests power from the air
}

\section{HIGHLY READ \\ on scitation.aip.org in December}

Researchers have built a metamaterial device that captures microwaves and turns them into electrical power.

Metamaterials are made up of

structures that are smaller than a given wavelength of electromagnetic radiation. When arranged in arrays, these structures can tune waves of that radiation in novel ways. Allen Hawkes and his colleagues at Duke University in Durham, North Carolina, used an array of five metamaterial cells, made from split copper circuits, to harvest microwave energy.

The microwaves cause an oscillating current in the material, and the copper circuits convert part of that current into usable power. When high-power microwaves were applied, the array produced enough direct current to charge a mobile phone.

Such a material could one day be built into devices and generate power by picking up energy from a mobile phone or Wi-Fi signals, the authors say.

Appl. Phys. Lett. 103, 163901 (2013)

they do this has not been clear. To find out, Richard Blumberg and Dennis Kasper of Harvard Medical School in Boston, Massachusetts, and their team studied a helpful intestinal bacterium, Bacteroides fragilis.

Mice colonized with

B. fragilis had fewer 'natural killer T cells' than did mice without the bacterium. But that effect was reduced in mice harbouring $B$. fragilis that lacked a gene responsible for making fatty compounds called sphingolipids.

Treating these mice with a purified B. fragilis sphingolipid restored normal natural killer $\mathrm{T}$-cell inhibition and protected the mice from chemically induced colitis. Animals exposed to the microbe early in life were more protected than those exposed later.

Cell 156, 123-133 (2014)

\section{CHEMISTR V}

\section{Molecules built in a bubble}

Chemical synthesis occurs more readily if the reaction takes place inside micrometresized compartments.

In theory, it is difficult to merge two molecules into one because of the decrease in entropy as the reaction proceeds. To overcome this hurdle, Andrew Griffiths at Strasbourg University in France and his colleagues studied chemical reactions occurring inside tiny water droplets suspended in oil.

They found that a fluorescent molecule built from two reagents formed more quickly in smaller droplets of water. A mathematical model indicated that molecules landing on a droplet's internal surface are more likely to merge with each other because the surface limits the available space and constrains the reactants' freedom of movement.

The results suggest that compartments, such as aerosol droplets or the pores in hydrothermal vents, could have assisted the organic reactions that are thought to have led to the origin of life. Phys. Rev. Lett. 112, 028310 (2014)

\section{$\rightarrow$ NATURE.COM}

For the latest research published by Naturevisit:

www.nature.com/latestresearch 